\title{
Providing remedial support to primary school learners within their zone of proximal development
}

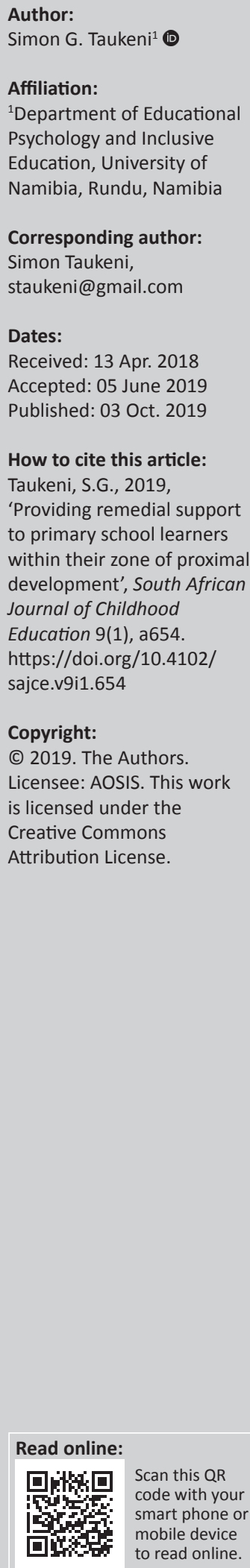

Background: One of the methods receiving the current attention in addressing poor performance and low learning achievements among lower primary school learners is through remedial teaching. The approach to provide remedial support was informed by Vygotsky's social development theory.

Aim: The objective of this study was to support primary school learners who failed with ungraded symbols in their first school term to obtain better passing symbols at the end of Term 2 and Term 3.

Setting: An intervention was carried out in 2016 academic year to provide remedial support to learners who were enrolled at Catholic AIDS Action Tonateni Centre in Oshakati town, Namibia.

Methods: Quantitative approach and descriptive design methods were used in this study. The first school term results were used as a baseline. A total of 12 learners (five boys and seven girls) from Grades 1 to 7 were randomly selected to participate in the remedial class. Data collection instruments included learners' school reports, homework books, class exercise books and test books. Statistical Package for Social Sciences was used to analyse descriptive statistics, namely, frequencies and percentages.

Results: Results showed that the participating learners obtained better passing symbols in the three identified subjects: Oshindonga first language, English second language and mathematics as depicted in their Term 2 and Term 3 school reports.

Conclusion: Remedial support demonstrated that learners who performed with poor symbols at the end of their first school term could still obtain better passing symbols in the second and third term provided they are supported to improve in their areas of learning difficulties.

Keywords: academic performance; English second language; Oshindonga first language; mathematics; remedial teaching; zone of proximal development.

\section{Introduction}

A country's successful development trajectory depends exclusively on its well-educated citizenry (Ganimian \& Mumane 2014). Namibia has achieved a noticeable increase in the enrolment rate in the early childhood education after it became independent in 1990. This significant advancement towards universal primary enrolment was confirmed by United Nations International Children's Emergency Fund (UNICEF) that by the end of 2009, the net primary enrolment (Grades 1-7) rate has reached $98 \%$ in 1992. The survival rate to Grade 8 also steadily increased from $52 \%$ in 1992 to $77 \%$ by 2008 . Even though there has been consistent increase in both enrolment and survival rates, the repetition rates have also been on increase for Grades 1, 5 and 8. The highest repetition rate was recorded at Grade 5 with 25.7\% in 2007 from the lowest level of 20.5\% in 2004 (UNICEF 2011).

Educational attainment levels are often quite low and even when learners are attending schools, sometimes very little is learned in most African developing countries (Pritchett 2013). Boone et al. (2015) suggest that to deal with low learning attainment, communities should provide remedial after-school classes to support learners whose academic achievements are low. Research supported evidence of different methods being used in developing countries addressing these low learning achievements. However, there have been reports of difficulties in implementing public policy (Kremer \& Holla 2009), which posed a great concern to effect the necessary progress in children's learning. The provision of remedial support to struggling learners after the normal school day has been shown to work in several settings (Muralidharan 2013). It was on that basis that a psychologist volunteered to provide remedial support to children who were being enrolled at Catholic AIDS Action Tonateni Centre in Oshakati town, Namibia. 
In their article, Sahito et al. (2017:2) assert that remedial support means 'providing a remedy or cure' to where is most needed. Therefore, the main aim of the remedial support was to provide a remedy based on the lack of competencies and skills identified from the learners' homework books, class exercises and test books. The remedial support was primarily aimed to support learners to improve in the areas where they lacked necessary competencies and skills considering their zone of proximal developments (ZPDs). Informed by Vygotsky's ZPD, the remedial support aimed at identifying what the children could do on their own without any assistance from the teacher and what they could not do without support (Vygotsky 1978).

\section{Zone of proximal development}

The concept ZPD was introduced by Lev Vygotsky during the late 1920s and developed it further until in 1934. According to Vygotsky in Shabani, Khatib and Ebadi (2010), ZPD means:

[T]he distance between the actual development level as determined by independent problem solving and the level of potential development as determined through problem solving under adult guidance or in collaboration with more capable peer. (p.86)

In other words, Vygotsky described ZPD as the difference between the actual level of development of what a child can do without support and the next level of development a child needs to attain with the support from the capable adult or peers.

Zone of proximal development concept is deep rooted in the social theory of learning that learners learn best with others collaboratively and cooperatively, and it is through such collaborative activities with more skilled persons that learners learn and internalise new ideas and skills (Shabani et al. 2010). It was for that understanding the volunteer used the learners' homework books, class exercise books and tests to have a better understanding of the learners' current and actual developments. Because the learners came from different schools, using their different homework activities and exercise books provided a great opportunity of sharing new ideas and methods from one another.

Roosevelt (2008) asserts that education based on ZPD perspective seeks to support learners by providing them with problem-solving tasks that are more challenging their actual level of development to work together with a more competent peer or teacher to finish the task. The idea behind is that after completing the task collaboratively with other peers or teacher, the learner would have acquired the necessary skills to complete the same task individually next time because his or her ZPD for that particular task would have been raised (Shabani et al. 2010).

\section{Scaffolding learners in Oshindonga first language}

When Namibia gained independence in 1990, the new Ministry of Education and Culture by then developed a new language policy for schools detailed in a document entitled: The language policy for schools: 1992-1996 and beyond (Ministry of Education and Culture [MEC] 1993). The policy directed learners to be taught primarily in their home language in Grades 1-3. English was to be a compulsory subject starting in Grade 1 and then become the main medium of instruction from Grade 4 and onward. According to MEC (1993), the goals of language policy were to utilise education as a tool to enhance learners' language and cultural identity, and to help learners become competent in English by the end of their 77-year primary education cycle. Namibia has 13 indigenous recognised languages, 10 African languages and three European languages (Frydman 2011).

Twelve learners recruited to receive remedial support in this study were all doing Oshindonga first language at their respective schools. The importance of the indigenous language in second-language achievement has been reported widely and there is strong support that children who are not taught in their indigenous language at lower school levels are likely to face challenges in mastering reading skills later in school (Prinsloo 2007; Wolfaardt 2005). It was for that reason the language policy in Namibia instructed learners to be taught in their indigenous languages during the first 3 years of their primary school education and from Grade 4 the medium of instruction should be changed to English (MEC cited in Mostert et al. 2012).

Efforts to transform education and empower the youth of the country to reach their full potential by embracing their cultural identity (Chavez 2016) have been initiated. One of the primary school teachers in the interview revealed that there is a general understanding in their community that Oshindonga teachers are less educated and therefore sometimes regarded as incompetent teachers, while those who know English are regarded as the highest qualified ones (Legere cited in Chavez 2016). Because of little motivation, there are only few teachers who qualified to teach in indigenous languages (Chavez 2016).

A number of challenges were noted as with regard to the full implementation of the language policy in Namibia. Of those challenges, schools were unable to provide indigenous language medium of instruction because of the lack of necessary teaching materials such as books. Another issue was the fact that Namibia is a diverse and inclusive nation where many learners with diverse indigenous languages were found in the same classroom and it became a challenge in selecting one indigenous medium of instruction. In an attempt to overcome these challenges, some schools have opted for English as medium of instruction from Grade 1 and as a result ended up neglecting one of the indigenous 
language (cited in Chavez 2016). All the learners who took part in the remedial class were doing Oshindonga as first language at their respective schools.

The teaching and learning process of indigenous languages, such as Oshindonga, faced noticeable challenges. In most cases, schools that strive for better indigenous language best practices lack the resources to do so. That is one of the reasons Brock-Utne and Holmarsdottir (2001) observe that the choice of languages offered by a school is most of the time because of financial reason rather than pedagogical one. It seems that international donors tend to support European languages than African languages and as a result there are more teaching and learning resources available in English than in the indigenous languages (Chavez 2016).

Many linguistic researchers emphasise the importance of the indigenous language, not only for second-language acquisition but also for general school achievement. For instance, Heugh (2005) argues that learners who are not taught in their indigenous language during early phases are likely to obtain poor grades and become underachievers in their later years in school. They will also likely find it difficult in other content-based subjects such as history and science. It was also observed with a concern in the reports of learners recruited for remedial class that many of them did not perform very well in Oshindonga first language.

\section{Scaffolding learners in English second language}

English is the second most widely spoken European language in the world, spoken by more than 350 million people, and the most widely taught as international language in schools (Sahito et al. 2017). In Namibia, English is taught in both private and public schools as a first and second language. It is also an official language used in Namibia. In 2008, about 243 schools had received permission from the Ministry of Education to use English as a medium of instruction from Grade 1 and onward. More schools had since adopted an English-only policy, partly because of the increase in parents who took their children out of schools that used indigenous language as a medium of instruction and enrolled them in schools that used English as medium of instruction (Tötemeyer 2010).

Even though English is given higher status, a test compiled and evaluated by the University of Namibia in 2011 revealed that $98 \%$ of teachers in Namibia were not sufficiently proficient in Basic English. However, nearly 63\% junior secondary teachers had poor knowledge of English, which was hampering teaching and learning process. The test further showed that about $70 \%$ of the teachers in senior secondary schools could not read and write Basic English (Kisting 2012). Teachers' lack of basic knowledge could be because of the fact that most of them had gone through a different education system, which did not use English as a medium of instruction. However, their lack of knowledge in English had disadvantaged some learners (Ministry of Basic
Education, Sport and Culture 2003). It was also clear from the performance of the learners who took part in remedial class that many of them lack basics. Their Term 1 results showed that none of the learners obtained an A or B symbol in their reports and five of the learners had failed with ungraded symbol in English.

\section{Scaffolding learners in mathematics}

The use of differentiated instruction method based on summative and formative assessment results by teachers to support their learners in mathematics is well documented. Differentiated instruction is a method of developing instruction based on learners' learning styles and needs (Beecher \& Sweeny 2008). The intervention was informed by the summative and formative assessment results of the learners. All remedial support activities were based on the assessment results; the aim was to identify their strengths and improve on their weaknesses to do better in the next two school terms.

Mathematics performance for struggling learners was linked to some of the psychological factors, namely, motivation, selfefficacy and engagement (Zhao et al. 2011). Other problems facing struggling mathematics learners include fluency in basic computation (Berg \& Hutchinson 2010), number sense concepts (Geary, Bailey \& Hoard 2009), fractional concepts (Courey et al. 2012) and mental arithmetic skills (Lee et al. 2011). Nearly all these problems were observed facing learners who took part in the remedial class. However, remedial support had somewhat helped many of the learners to develop basic skills needed to solve mathematical problems. DeFilippis (2014) suggests that teachers should advance proficient level in mathematics beyond the traditional lecture-based teaching and adopt an inclusive approach such as individualised approach to meet all learners' needs.

\section{Research methodology}

Quantitative approach and descriptive research design were used to carry out the research. Chudleigh and Smith (2015) list quantitative approach to include the following designs: descriptive, correlation, quasiexperimental research and experimental research design. The overall methodological approach was to describe the current status of children who took part in the remedial class by using first school term results as a baseline and consequently the second and last term that would depict their current status. Descriptive design was more appropriate for this research whose main aim was to support primary school learners who failed with ungraded symbols in their first school term to obtain better passing symbols at the end of Term 2 and Term 3 and assess the effectiveness of the intervention (LoBlondo-Wood \& Haber 2014). It was further appropriate because descriptive design seeks for the development of future quantitative research hypothesis (Burns \& Grove 2011). 


\section{Population and sample}

The target population of the intervention consisted of all learners who failed with ungraded symbols in their first school term. A sample consisted of 12 learners (five boys and seven girls) from Grades 1 to 7 . Further justification of how sample was selected is discussed in the section 'Sampling technique'.

\section{Sampling technique}

Learners were randomly selected based on the Term 1 performance, as shown in their school reports. Subjects were only picked because learners scored with ungraded symbols and other poor symbols. Therefore, the remedial support was only focusing on scaffolding learners' learning needs on the three school subjects: Oshindonga first language, English second language and mathematics of which learners performed poorly. It was a requirement for all the registered learners at the centre to provide their school reports at the end of every school term. Learners who underperformed and failed with ungraded symbols as indicated in their reports were invited to form a remedial class. About two learners who performed well were purposively invited to join the class and serve as capable peers to assist other learners.

\section{Remedial aim, timeline and duration}

The remedial support was facilitated by a volunteer, who is a psychologist, together with some capable peers to support other learners who performed poorly in their first school term. The remedial support was seeking to improve learners' learning needs in Oshindonga first language, English second language and mathematics. These subjects were purposively selected because none of the learners obtained an A symbol in Term 1 as a baseline. The intervention sought to at least assist some learners to gain an A symbol in the identified subjects.

Remedial support was aimed to scaffold learners according to their identified learning needs. Documents analysed revealed the learning needs in terms of reading and writing both in Oshindonga and English. Therefore, remedial activities for Grades 1-3 covered supporting learners about learning alphabetical letters and numbers. Learners were also given tasks to write and read short stories in both languages. The main aim was really to build learners' vocabulary, and to improve their comprehension and the use of tenses. Both the volunteer and capable peers provided necessary assistance and corrections during the tasks.

Activities for learners in Grades 4-7 were mainly about addressing the lack of writing skills as reflected in the participating learners' Oshindonga and English homework and class activity books. Learners wrote different stories based on the given themes during the remedial class. They were also given activities on grammar especially to complete the sentences using tenses for comprehension purposes. In mathematics subject, the remedial support included tasks that they were doing at school, namely, addition, subtraction, multiplication and division. Fractional concept and basic computational tasks were done during the remedial class.
TABLE 1: Remedial support timetable.

\begin{tabular}{llc}
\hline Day of the week & Subject & Time \\
\hline Monday & Oshindonga first language & 15:00-17:00 \\
Tuesday & English second language & $15: 00-17: 00$ \\
Wednesday & Mathematics & $15: 00-17: 00$ \\
Thursday & General consultation & $14: 00-17: 00$ \\
Friday & Sport and drama & $14: 00-17: 00$ \\
\hline
\end{tabular}

The intervention was carried out for only 2 months per term. The timeframe was informed by the school term calendar of 2016 academic year. It started in the second school term from June to July 2016 and in third term from September to October 2016. The class was facilitated from Monday to Wednesday from 15:00 to 16:00 for children in Grades 1-3 and 16:00 to 17:00 for children in Grades 4-7. Usually, time from 13:00 to 15:00 was reserved for children to arrive at the centre from school and to finish eating their meal of the day. Remedial support timetable is presented in Table 1.

\section{Data collection}

The researcher used document analysis, including learners' school reports, homework books, class exercise books and test books to collect data. These instruments provided information regarding the participating learners' areas of difficulty. As a facilitator, there was a need to identify what each learner could do and what he or she could not do, and that information was obtained from the learners' homework books, class activity books and test books as part of their formative assessment.

\section{Data analysis}

Descriptive statistics in terms of frequencies and percentages were analysed with Statistical Package for Social Sciences and presented in tables. Data analysis included participants' demographical details and performance in the three subjects: Oshindonga, English and mathematics per each school term.

\section{Ethical considerations}

A researcher wrote consent letters for every invited child to take to their parents and caregivers for signature. Only children whose parents had signed and given consent were allowed to partake in remedial class activities. All participating learners agreed to attend every class after school and they were all informed about their voluntary participation in the remedial class.

This is the scholarly work of the author. Where other people's work has been used (e.g. from printed sources, Internet or any other source), this has been properly acknowledged and referenced. This research study has never been published or sent anywhere for publication. Participants' personal identity remains strictly confidential.

\section{Results}

Demographical details of learners are the first to be presented in Table 2 followed by the results of learners' performance from Term 1 to Term 3, as presented in Tables 3-5. 
TABLE 2: Age and sex $(N=12)$.

\begin{tabular}{lccc}
\hline Age & \multicolumn{2}{c}{ Sex } & Total (\%) \\
\cline { 2 - 3 } & Female (\%) & Male (\%) & \\
\hline 6-8 years & 42.9 & 80.0 & 58.3 \\
9-12 years & 57.1 & 20.0 & 41.7 \\
\hline Total & $\mathbf{1 0 0 . 0}$ & $\mathbf{1 0 0 . 0}$ & $\mathbf{1 0 0 . 0}$ \\
\hline
\end{tabular}

TABLE 3: Oshindonga first language $(N=12)$.

\begin{tabular}{lcccccc}
\hline Symbols & Term $\mathbf{1}$ & $\mathbf{\%}$ & Term $\mathbf{2}$ & $\mathbf{\%}$ & Term $\mathbf{3}$ & $\mathbf{\%}$ \\
\hline$A$ & 0 & 0.0 & 0 & 0.0 & 0 & 0.0 \\
$B$ & 2 & 16.7 & 4 & 33.3 & 2 & 16.7 \\
$C$ & 3 & 25.0 & 4 & 33.3 & 4 & 33.3 \\
$D$ & 4 & 33.3 & 3 & 25.0 & 4 & 33.3 \\
$E$ & 2 & 16.7 & 0 & 0.0 & 1 & 8.3 \\
$U$ & 1 & 8.3 & 1 & 8.3 & 1 & 8.3 \\
\hline Total & $\mathbf{1 2}$ & $\mathbf{1 0 0 . 0}$ & $\mathbf{1 2}$ & $\mathbf{1 0 0 . 0}$ & $\mathbf{1 2}$ & $\mathbf{1 0 0 . 0}$ \\
\hline
\end{tabular}

TABLE 4: English second language $(N=12)$.

\begin{tabular}{lcccccc}
\hline Symbols & Term $\mathbf{1}$ & $\mathbf{\%}$ & Term $\mathbf{2}$ & $\mathbf{\%}$ & Term $\mathbf{3}$ & $\mathbf{\%}$ \\
\hline A & 0 & 0.0 & 0 & 0.0 & 0 & 0.0 \\
B & 0 & 0.0 & 0 & 0.0 & 0 & 0.0 \\
C & 2 & 16.7 & 3 & 25.0 & 5 & 41.7 \\
D & 2 & 16.7 & 0 & 0.0 & 1 & 8.3 \\
E & 3 & 25.0 & 4 & 33.3 & 5 & 41.7 \\
U & 5 & 41.7 & 5 & 41.7 & 1 & 8.3 \\
\hline Total & $\mathbf{1 2}$ & $\mathbf{1 0 0 . 0}$ & $\mathbf{1 2}$ & $\mathbf{1 0 0 . 0}$ & $\mathbf{1 2}$ & $\mathbf{1 0 0 . 0}$ \\
\hline
\end{tabular}

TABLE 5: Mathematics $(N=12)$

\begin{tabular}{lcccccc}
\hline Symbols & Term $\mathbf{1}$ & $\mathbf{\%}$ & Term $\mathbf{2}$ & $\mathbf{\%}$ & Term 3 & $\mathbf{\%}$ \\
\hline A & 0 & 0 & 3 & 25.0 & 2 & 16.7 \\
B & 2 & 16.7 & 2 & 16.7 & 2 & 16.7 \\
C & 1 & 8.3 & 3 & 25.0 & 2 & 16.7 \\
D & 4 & 33.3 & 0 & 0 & 2 & 16.7 \\
E & 4 & 33.3 & 4 & 33.3 & 3 & 25.0 \\
U & 1 & 8.3 & 0 & 0 & 1 & 8.3 \\
\hline Total & $\mathbf{1 2}$ & $\mathbf{1 0 0 . 0}$ & $\mathbf{1 2}$ & $\mathbf{1 0 0 . 0}$ & $\mathbf{1 2}$ & $\mathbf{1 0 0 . 0}$ \\
\hline
\end{tabular}

Table 2 shows that learners who took part in the remedial class, the majority $(80 \%)$ were male of $6-8$ years old and only a few $(20 \%)$ male were of 9-12 years old. As with regard to female in the remedial class, more than a half (57.1\%) were of 9-12 years old and about $42.9 \%$ were of 6-8 years old.

\section{Results per subjects}

The main objective of this research was to describe the difference between variables to develop hypothesis that could be tested in further quantitative research studies. The aim of the study was to describe how participating learners had performed in Term 2 and Term 3, which they performed poorly in Term 1. Table 3 presents results of Oshindonga first language.

Table 3 shows that using Term 1 as a baseline, one could see that there has been a positive consistent improvement in Oshindonga first language in general. The notable improvement was achieved with the increase of B symbols from $16.7 \%$ to $33.3 \%$ in Term 2 . One major concern, however, observed was that none $(0 \%)$ of learners obtained an A symbol in their own mother tongue in all the three school terms. Table 4 presents results for English second language.
Using Term 1 as a baseline, Table 4 shows that the majority of learners obtained C and D symbols in both Term 2 and Term 3. There has been a positive improvement on the number of learners who failed English second language with an ungraded symbol from $41.7 \%$ to only $8.3 \%$ in Term 3 . Clearly, there has been improvement in both Term 2 and Term 3. In general, the result shows that not a single learner managed to obtain either an A or B symbol in all three terms. Table 5 presents results of how learners performed in mathematics

Table 5 reports a significant improvement on the number of learners who obtained an A symbol in mathematics from $0.0 \%$ to $25.0 \%$ in Term 2 and $16.7 \%$ in Term 3. Interestingly, there was no change recorded on the number of learners who obtained a B symbol; they all maintained $16.7 \%$ in all three terms. Even though the intervention has produced positive results in general, one of the learners could not obtain a passing symbol in Term 3.

\section{Discussion}

The descriptive results showed that the participating learners performed significantly well in mathematics subject in Term 2 and Term 3 than in Term 1. The differences were also recorded in Oshindonga first language both in Term 2 and Term 3 as compared to Term 1 . It seemed, however, that both Oshindonga and English need more improvement to at least ensure that learners could obtain an A or B symbols. It was, however, surprising to note that not even a single learner managed to obtain an A or B symbol in English secondlanguage. Learners' general performance in Oshindonga first language was also not satisfactory. Mostert et al. (2012) found that teaching materials are important for the development of the language in schools. If these resources (e.g. textbooks, technological resources, any print materials) are lacking at schools, there is no doubt that the learning of any subject (whether language or content) becomes difficult if not impossible to learners.

This study confirmed a concern pattern of poor performance in English, Oshindonga and mathematics for primary education learners (Chavez 2016). Because of its limited focus, the study did not investigate why learners performed poorly in the stated school subjects. It would be important for further research to be carried out to determine the root causes of poor performance in English, Oshindonga and mathematics in Namibian schools. Clearly, this research only focused on the results based on scaffolding effort that was provided to a small sample of learners enrolled at Tonateni Centre only.

In mathematics, learners had improved their symbols in the second and third terms. However, one of the learners did not pass the subject at the end of the third term. Van Steenbrugge, Valcke and Desoete (2010) observed that there are some curriculum topics present difficulties in mathematics, namely, fractions, long division, time, numerical proportions, scale and metric system. Most of the participating learners in the 
remedial class experienced difficulties in most of those listed curriculum topics, as seen in their homework books, class activities and test books.

Even though there could have been some other interventions, for example, at school or home, the results of remedial support had shown some positive improvements in the targeted three subjects. These positive improvements could be attributed to the fact that the activities given to the learners at school could have fallen outside their ZPD and these learners could not get support from the teacher or from one of their capable peers or support from home to complete their work. However, Shabani et al. (2010) state that the focus of teaching should be on school activities inside the ZPD of which the learner can do or cannot do by him or herself but has the potential to accomplish the task with the guidance of others. Cole and Cole (2001) agree that the concept of proximal development demonstrates the need of support to go slightly beyond the learner's current ability and developing his or her existing ability even further. This idea was clearly demonstrated and confirmed by participating learners in the remedial class. Many of the participating learners showed the need of support to complete their schoolwork and that came out in their results from Term 1 to Term 3.

\section{Strengths and limitations}

The strengths of this study were demonstrated by the use of summative and formative assessment results that provided a baseline to track the progress of the participating learners from Term 1 to Term 3. This simply means that without summative and formative assessment, the research could not have been carried out. Specifically, formative assessment results guided the remedial support activities and provided clearly the learners' areas of difficulty. It was clear to assess what learners were good at and what they were still in need of support to overcome the specific learning difficulty. This research also contributed scientific knowledge on the importance of remedial teaching to scaffold learners who seemed left behind. This research provided a good base for future quantitative research studies to explore more on the remedial teaching intervention.

Finally, some limitations of this research are that results should not be generalised to the entire population of learners who were enrolled at Tonateni Centre; this is simply because of the small sample size that only included 12 learners who were specifically selected to be part of remedial class. Generally speaking, as a faith-based organisation, the idea behind creating a remedial class was only to support our vulnerable children and to see them progressing in their education. The scaffolding effort assisted the targeted children to move on to the next grade and that was very important to the organisation as part of its social responsibility.

\section{Implications}

Results of the remedial class demonstrated that learners who performed below average had the potential to perform much better given the necessary support from a capable adult and peers. Results implied that either teachers used to give learners tasks without scaffolding them or the tasks were not within the learners' ZPDs. Ball, Lubienski and Mewborn (2001) concur that teachers should try to understand the content area of difficulties facing their learners and provide support to those learners who most need it. The implication of this intervention was that what a learner performed with support helped the learner to do better on his or her own in the next terms (Shabani et al. 2010). Results further implied that teachers were either not implementing remedial teaching at their respective schools or they were not doing enough to support learners who needed support the most. Like what Vygotsky (1978) suggested that by creating a learner's ZPD we are helping the learner's current and future learning.

\section{Conclusion}

The study was carried out to scaffold learners who performed with ungraded symbols in Term 1 in the subjects such as Oshindonga first language, English second language and mathematics. The intervention has demonstrated that learners who performed with ungraded and poor symbols at the end of their first school term had improved their performance in Oshindonga, English and mathematics in Term 2 and Term 3. If well planned and implemented, remedial support could make a big difference in terms of addressing learners' learning needs. Further comparative research of two groups (comparative and control groups) is recommended.

\section{Acknowledgements}

The author wishes to thank the Catholic AIDS Action, in particular, Tonateni Centre in Oshakati for the support granted during remedial classes with the participants. In the same vein, the participation of all selected children is highly acknowledged.

\section{Competing interests}

The author declares that he has no financial or personal interest that may have inappropriately influenced him in writing this article.

\section{Authors' contributions}

S.G.T. was responsible for the entire article. The article is part of the author's community service.

\section{Funding information}

The author acknowledges the support provided by the Catholic AIDS Action under the After-School Program in terms of stationeries, a venue and other related materials to conduct the remedial support to the learners.

\section{Data availability statement}

Data for this study are available from the author upon request. 


\section{Disclaimer}

The views and opinions expressed in this article are those of the author(s) and do not necessarily reflect the official policy or position of any affiliated agency of the authors.

\section{References}

Ball, D.L., Lubienski, S.T. \& Mewborn, D.S., 2001, 'Research on teaching mathematics: The unsolved problem of teachers' mathematical knowledge', in V. Richardson (ed.), Handbook of research on teaching, 4th edn., American Educational Research Association, Washington, DC.

Beecher, M. \& Sweeny, S.M., 2008, 'Closing the achievement gap with curriculum enrichment and differentiation: One school's story', Journal of Advanced Academic 19(3), 502-530. https://doi.org/10.4219/jaa-2008-815

Berg, D.H. \& Hutchinson, N.L., 2010, 'Cognitive processes that account for mental addition fluency differences between children typically achieving in arithmetic and children at-risk for failure in arithmetic', Learning Disabilities: A Contemporary and children at-risk for failure in arithmetic', Learning Disabilities: A Conter
Journal 8(1), 1-20. https://doi.org/0.1111/j.1467-8624.2007.01069.x

Boone, P., Camara, A., Eble, A., Elbourne, D., Fernandes, S., Frost, C. et al., 2015 'Remedial after-school support classes offered in rural Gambia (The SCORE trial): Study protocol for a cluster randomized controlled trial', Trials 16(1), 574. https:// Study protocol for a cluster randomized

Brock-Utne, B. \& Holmarsdottir, H., 2001, 'The choice of English as medium of instruction and its effects on the African languages in Namibia', International Review of Education 47(3-4), 293-322.

Burns, N. \& Grove, S.K., 2011, Understanding nursing research: Building an evidencebased practice, 5th edn., Elsevier Saunders, Maryland Heights, MO.

Chavez, A., 2016, 'Rights in education and self-identity: Education and language of instruction in Namibia', International Education Studies 9(3), 189-196. https:// doi.org/0.5539/ies.v9n3p189

Chudleigh, J. \& Smith, J., 2015, 'Research essentials: Introduction to quantitative research', Nursing Children and Young People 27(3), 12.

Cole, M. \& Cole, S., 2001, The development of children, 4th edn., Scientific American Books, New York.

Courey, S.J., Balogh, E., Siker, J.R. \& Paik, J., 2012, 'Academic music: Music instruction to engage third-grade students in learning basic fraction concepts', Educational Studies in Mathematics 81(2), 251-278.

DeFilippis, C., 2014, 'Perceptions of teachers on instructing remedial Mathematics students', Doctor of Education thesis, Walden University.

Frydman, J., 2011, 'A critical analysis of Namibia's English-only language policy', 40th Annual Conference on African Linguistics, Cascadilla proceedings project, Somerville, MA

Ganimian, A.J. \& Mumane, R.J., 2014, 'Improving educational outcomes in developing countries: Lessons from rigorous evaluation', National Bureau of Economic Research, viewed 10 April 2018, from http://www.nber.org/papers/w20284.pdf.

Geary, D., Bailey, D.H. \& Hoard, M.K., 2009, 'Predicting Mathematical achievement and mathematical learning disability with a simple screening tool: The number sets test', Journal of Psychoeducational Assessment 27(3), 265-279. https://doi. org/0.1177/0734282908330592

Heugh, K., 2005, 'Mother-tongue education is best', HSRC Review 3(3), 6-7. https:// doi.org/10.1080/00313831.2010.493341

Kisting, D., 2012, 'Namibia's language policy is poisoning its children', viewed 15 March 2016 from https://www.theguardian.com/education/2012/jan/10/namibia-english-crisis.
Kremer, M. \& Holla, A., 2009, 'Improving education in the developing world: what have we learned from randomized evaluations?' Annual Review Economics 1, 13-542.

Lee, K., Ng, S.F., Bull, R., Pe, M.L. \& Ho, R.H.M., 2011, 'Are patterns important? An investigation of the relationship between proficiencies in patterns, computation, executive functioning and algebraic word problems',, Journal of Educational Psychology 103 (2), 269-281. http://doi.org/10.1037/a0023068

LoBlondo-Wood, G. \& Haber, J., 2014. Nursing research: Methods and critical appraisal for evidence based practice, Mosby Elsevier, St. Louis.

McAlister, T., Rolstad, K. \& MacSwan, J. (eds.), 2003, Proceedings of the 4th International Symposium on bilingualism 30 April - 03 May, Somervile, MA Cascadilla Press, pp. 2368-2375.

Ministry of Basic Education, Sport and Culture (MBESC), 2003, The language policy for schools in Namibia, Upgrading African Languages Project (Afril.a), Windhoek.

Ministry of Education and Culture, 1993, The language policy for schools 1992-1996 and beyond, Longman/ODA, Windhoek.

Mostert, M.L., Hamunyela, M., Kasanda, C., Smit, T.C., Kangira, J., Zimba, R.F. et al., 2012, 'Views and preferences of parents, teachers and principals on the implementation of the language policy in primary schools in Namibia: An explorative study in the Khomas region', Journal for Studies in Humanities and Social Sciences 1(2), 167-178.

Muralidharan, K., 2013, 'Priorities for primary education policy in India's 12th fiveyear plan', India Policy Forum 9, 1-46.

Prinsloo, D., 2007, 'The right to mother tongue education in multidisciplinary normative perspective', Southern African Linguistic and Applied Language Studies 25(1), 27-43. https://doi.org/10.2989/16073610709486444

Pritchett, L., 2013, The Rebirth of Education: Schooling ain't learning. Washington, DC: Center for Global Development, Washington, DC.

Roosevelt, F.D., 2008, 'Zone of proximal development', in N.J. Salkin and K. Rasmussen (eds.), Encyclopedia of educational psychology, Vol 1, pp. 1017-1022, Sage, Thousand Oaks, CA.

Sahito, Z., Siddiqui, A., Khawaja, M., Shaheen, A., Saeed, H. \& Laghari, S.H., 2017 'Teaching of remedial English and the problems of the students: A case of University of Sindh, Jamshoro, Sindh, Pakistan', World Journal of English Language 7(1), 1-10. https://doi.org/10.5430/wjel.v7n1p1

Shabani, K., Khatib, M. \& Ebadi, S., 2010, 'Vygotsky's Zone of Proximal Development Instructional implications and teachers professional development', English Language Teaching 3(4), 237-248.

Tötemeyer, A., 2010, Multilingualism and the language policy for Namibian schools, PRAESA, Cape Town.

UNICEF, 2011, 'Improving quality and equity in education in Namibia: A trend and gap analysis', viewed 15 March 2018, from https://www.unicef.org/namibia/ UNICEF_2011_Ninnes_Trends_and_Gaps_final_combined.pdf.

Van Steenbrugge, H. Valcke, M. \& Desoete, A, 2010, 'Mathematics learning difficulties in primary education: Teachers' professional knowledge and the use
of commercially available learning packages', Educational Studies 36(1), 59-71. of commercially available learning packages',
https://doi.org/10.1080/03055690903148639

Vygotsky, L.S., 1978, Mind in society: The development of higher psychological processes, Harvard University Press, Cambridge, MA.

Wolfaardt, D., 2005, 'Namibia: A case for a gradual transitional bilingual programme', in J. Cohen, K.

Zhao, N., Valcke, M., Desoete, A., Verheaghe, J. \& Xu, K., 2011, 'A multilevel analysis on predicting Mathematics performance in Chinese primary schools: Implications for practice', Asia-Pacific Educational Research 20(3), 503-520. 